\title{
POLÍTICA PÚBLICA RESPECTO A LA ADOPCIÓN DE MENORES EN PUERTO RICO ¿TIEMPO DE REVISIÓN?
}

\author{
Isabel Montañez Concepción ${ }^{1}$ \\ Astrid E. Santiago Orria ${ }^{2}$ \\ Rose Marrero Teruel $^{3}$
}

\section{Resumen}

La adopción de menores es un acto legal y social que reafirma los valores de la sociedad que lo practica. En el presente artículo se discute el contexto histórico, político, social y cultural en el cual se da la adopción de menores. Se plantea las influencias de los diversos contextos en la construcción social de la adopción así como en la elaboración de las políticas públicas aprobadas en Puerto Rico especialmente las leyes 8 y 9 de enero de 1995. Se destaca el rol de la investigación y el trabajo social mediante una descripción de investigaciones realizadas en otros entornos así como en Puerto Rico. Como reflexión final se invita a buscar alternativas para que el acto de adoptar esté revestido del resguardo de la dignidad de todas las partes. Se propicia el que las parejas, mujeres u hombres que no deseen conservar la custodia de su descendencia puedan entregarlo al Estado para que ejerza su rol de "Parens Patrie"; lo cual previene la intervención que fuerza y despoja. Finalmente se concluye que la profesión de trabajo social por su función y fundamentos está llamada a iniciar acciones encaminadas a redefinir la política pública del Estado.

Palabras claves: adopción, menores, política pública, construcción social de la adopción.

\footnotetext{
${ }^{1}$ Catedrática Auxiliar en el Departamento de Trabajo Social, Universidad de Puerto Rico en Río Piedras.

${ }^{2}$ Estudiante del Programa Doctoral de la Escuela Graduada de Trabajo Social Beatriz Lassalle, Universidad de Puerto Rico en Río Piedras.

${ }^{3}$ Trabajadora Social en el Decanato de Estudiantes, Universidad de Puerto Rico en Río Piedras.
} 


\section{Abstract}

The adoption of children is a legal and social activity that reaffirms the values of a society. This article discusses the historical, political, social, and cultural context of the adoption of minors. It presents the influence of different contexts in the social construction of adoption, as well as the creation of public policy approved in Puerto Rico, especially laws number 8 and 9 of January 1995. The role of research and social work is highlighted through the description of studies in Puerto Rico and other places. The authors made an invitation to consider alternatives that protect the human dignity of everybody in the process of adoption. It promotes the possibility for couples, women and men to give up their "Parens Patrie" to the State when they do not wish to keep custody of their children. This will avoid interventions by force and deprivation. Finally, it concludes that social work a profession, by its foundation, should have the responsibility to initiate actions toward the redefinition of public policy.

Key words: adoption, minors, public policy, social construction of adoption.

\section{Introducción}

La adopción de menores además de ser un acto legal y social que reafirma los valores de la sociedad que lo practica se ha convertido en una manera de solucionar los problemas de diversas personas y/o instituciones. Aunque tal práctica es aceptada y validada por la sociedad puertorriqueña desde hace siglos, mediante legislación, es imprescindible que reflexionemos sobre los fundamentos sociales que la sostienen. La sociedad es un grupo en constante cambio motivado por las experiencias que enfrenta, las cuales demandan miradas enfocadas en la realidad que ellas generan. Con frecuencia los seres humanos revisan sus posturas ante eventos que le afectan como individuos alterando la organización de los valores que respaldan sus acciones. ¿Sobre que realidad social está cimentada la ley que regula la adopción? ¿Desde que voces se ha construido esa realidad? ¿Debe continuar la adopción mirándose como remedio al maltrato a menores? ¿Qué otras voces deben ser escuchadas para construir una visión menos restrictiva en el empeño de entender la adopción?

La adopción desde su origen está cimentada sobre bases caritativas y humanísticas. Como concepto y manifestación de amparo a otro, se origina en la India, por razones religiosas llega a los hebreos y por las conquistas políticas del Imperio Romano se difunde por otros lugares, insertándose en el 
derecho romano, del cual somos herederos (Quiñonez-Torres, 1996). En el derecho romano la adopción se utilizó como forma de ingresar a una familia para la continuidad de la estirpe; con fines económicos, sociales y políticos. Por ello, cuando se carecía de descendencia natural se adoptaba un "extraño" con tales propósitos. Se creaba, artificialmente, una patria potestad para permitir el ingreso de ese 'extraño' al grupo familiar, con una posición jurídica equivalente a la de un hijo o descendiente natural (Pierluisi, 1994).

En el cristianismo la adopción es un tema central y altamente discutido en términos espirituales o místicos desde sus inicios (Camacho, Delgado y Díaz, 2005). Las civilizaciones que fueron impactadas por los romanos entraron en contacto con el concepto y el procedimiento que lo acompañaba, siendo practicado y adaptado a su realidad económica, social y temporal. En el derecho Justiniano aparece la distinción entre la adopción plena y menos plena. La adopción plena se daba cuando el adoptante era ascendiente consanguíneo del adoptado. Sus efectos eran todos los inherentes a la patria potestad. En la menos plena, el adoptado se conservaba dentro de su grupo familiar biológico y adquiría prácticamente sólo el derecho a suceder abintestato al adoptante (Pierluisi, 1994).

La figura de la adopción la recoge el Código Francés, siguiendo el modelo Justiniano de la adopción menos plena. Siguieron el mismo modelo, el Código italiano de 1885, el suizo y el español. El Código alemán se apartó de este modelo y estableció la equiparación del adoptado con el hijo natural. En Inglaterra se reglamentó la adopción en 1926 al aprobarse el "Adoption Act". Este siguió el concepto de la adopción plena. En los Estados Unidos la adopción la regula cada estado, mediante leyes especiales. Estas varían de acuerdo al trasfondo civilista o anglosajón existente en cada jurisdicción (Pierluisi, 1994).

Con la extensión del Código Civil Español, en 1889 llega la institución de la adopción a Puerto Rico. En los primeros años de vigencia del Código Civil Español en Puerto Rico, la naturaleza de la adopción era contractual. Sus efectos eran los de proveer al adoptado los derechos de alimentos, apellidos del adoptante y derechos sucesorios, cuando así se pactaba. El adoptado no salía de su familia natural y de ordinario conservaba todos sus derechos en ella. Quedaba bajo la patria potestad y protección del adoptante (Tribunal General de Justicia, 2004). Al adoptarse el Código Civil de 1902, fue de las pocas materias en que no se siguió estrictamente el Código Civil Español. Se aprobaron los Artículos 132 y 133 del Código Civil copiados del Artículo 
214 del Código Civil de Louisianna (Tribunal General de Justicia, 2004). La adopción como se conoce actualmente irrumpe con el derecho contemporáneo luego de la Primera Guerra Mundial, ante el gran número de huérfanos (Camacho, Delgado y Díaz, 2005).

El nuevo enfoque abandonó el concepto clásico de que la adopción era un contrato privado por la fijación de una intervención activa del estado a través de agencias apropiadas para salvaguardar el interés de la familia y especialmente del adoptado (Tribunal General de Justicia, 2004). La legislación moderna sobre adopción reconoce una diferencia básica: los derechos y las necesidades de los padres versus el bienestar del menor. De acuerdo a su interpretación del amparo a los que carecían de familia, y de la continuidad de la raza, las parejas eran responsables de procrear y así continuaba la especie, la adopción pasó a ser el vehiculo de ingresar a una nueva familia a un sujeto.

Históricamente la adopción ha estado revestida de una intención de dar a un menor unos padres, que aunque no tienen vínculo sanguíneo, pueden subsanarlo con cuidados y protección. Ander-Egg (1995) plantea la adopción como un acto jurídico mediante el cual un adulto toma a su cargo voluntariamente, a un niño como hijo propio. Sin embargo, reconoce que la adopción tiene nuevos significados y contenidos más humanos que legales, alejados de la intención de suplir una necesidad de una pareja sin hijos y enfocados en llenar una necesidad de un menor sin padres y sin hogar. La acción de la madre o padre que opta por entregar a su hijo/a para que otra persona lo críe, guarda relación directa con el amor que siente por la criatura. A pesar de la crítica estigmatizante que pueda generar la sociedad y el estado, ellos entienden que la entrega responde más al amor que al rechazo, debido a que la adopción busca garantizar una mejor condición de vida. La importancia de estudiar a fondo las aptitudes de los posibles padres para el menor, surge del reconocimiento de la centralidad de la figura del menor. Asimismo Quiñónez-Torres (1996) señala que la figura jurídica de la adopción imita el fenómeno biológico de la paternidad o de la paternidad natural. Otros escenarios, como la relación política, social, económica con los Estados Unidos de América y la inserción en los reclamos internacionales de proteger los derechos humanos, enfocados en la niñez, también son fuente importante para la promoción y creación de la política pública puertorriqueña en relación con la adopción.

La Asamblea General de la Naciones Unidas trabajó en la elaboración de un documento que fuera aceptado por sus miembros, como un decreto protector 
de los menores, con reconocimiento mundial. Sin embargo, antes de la aprobación de la Convención sobre los Derechos del Niño, las normas de derechos humanos que se debían aplicar a todos los miembros del género humano habían sido plasmadas en varios instrumentos jurídicos, como por ejemplo los pactos, las convenciones y las declaraciones, igual que había ocurrido con las normas relativas a las cuestiones específicas que atañen a la niñez. Pero fue el 20 de noviembre de 1989 cuando las normas sobre los niños y niñas se agruparon en un único instrumento jurídico, aprobado por la comunidad internacional, donde se describieron de forma inequívoca los derechos que corresponden a todos los niños y las niñas, independientemente de su lugar de nacimiento o de sus progenitores, de su género, religión $u$ origen social. Este régimen de derechos estipulados en la Convención son los derechos de todos los niños y niñas del mundo (UNICEF, 2000).

El documento otorga al niño y niña ciudadanía mundial con derechos a recibir atención para llenar sus necesidades de parte de las personas adultas y en el cual se refuerza la dignidad humana. Un elemento destacable de ese documento es que subraya y defiende la función de la familia en la vida de niños y niñas, reconoce el derecho que tienen a tener un apellido, una nacionalidad, una familia, una vivienda, cuidados, educación y protección frente a cualquier ataque contra su desarrollo fisco, mental y moral. La responsabilidad en el cumplimiento de esos derechos es compartida por los padres, madres y por el Estado (UNICEF, 2000). Los padres y madres biológicos que se desprenden de su prole están resguardando esos derechos.

\section{Política de adopción en Puerto Rico}

En Puerto Rico, en el año 1953, la Asamblea Legislativa aprobó las leyes 85 y 86 para uniformar todas las disposiciones procesales y sustantivas referentes a la situación de la adopción (Cámara de Representantes-Comisión de lo Jurídico, 1994). A partir de ese momento la institución de la adopción comienza a ser tratada como un aspecto que refleje la cultura y valores de la sociedad puertorriqueña, llegando a ser cualificada como una "ley autóctona, ajustada a la realidad de la vida actual de la sociedad puertorriqueña" (Exposición de Motivos, Ley 8,1995).

La relación política con los Estados Unidos obliga a la sociedad puertorriqueña a considerar en los asuntos de protección de menores y los remedios para los mismos, la visión que esa sociedad tiene. La concesión de fondos federales, consignados en el Adoption Assistance and Child Welfare 
Act, 1980 establece los parámetros y pautas en cuanto al reembolso de fondos para diversos programas de adopción. Esta ley se refiere a las oportunidades de rehabilitación, en términos del tiempo que se le concede, que tienen los padres biológicos de menores removidos y su reintegración al hogar (Discusión del proyecto 899, 1994 Senado de Puerto Rico, pág. 25). Como parte del plan de servicios se promovía agotar los esfuerzos de reintegrar a menores al hogar de origen, produciéndose su acumulación en hogares temporeros, impidiendo que se trazara un plan de adopción como opción permanente que beneficiara al menor. La intervención social con progenitores de menores en hogares sustitutos no alcanzaba a completar las metas debido a factores como, la retirada de los padres ante la remoción forzada de menores. Esto debido a que no se consideraban aptos y aptas para atender al menor según las normas sociales y a los pocos recursos humanos y fiscales para ayudarles en el proceso de preparación para la reunificación familiar. Otro aspecto que subyace a las leyes de adopción, es la insatisfacción de parejas que deseaban llenar la necesidad de la paternidad/maternidad y no encontraban a los menores ya que estos aún permanecían bajo la tutela del Estado esperando regresar al hogar de origen, provocando que solicitaran revisión de las leyes y la política pública que las sustentaba.

\section{Construcción de la política pública de adopción}

La influencia de los diversos contextos presentados incidió en la elaboración de la política pública contenida en las leyes 8 y 9 de enero de 1995. El propósito de la Ley 8 del 19 de enero de 1995 es enmendar el articulado sobre Adopción en el Código Civil de Puerto Rico de 1930, regulando en la dimensión sustantiva lo relacionado a la materia de adopción y de protección de menores. Establece la necesidad de revisar las disposiciones relativas a la adopción así como las relativas a la patria potestad y tutela a fin de flexibilizar la institución de la adopción para que pueda ser utilizado por quien desea adoptar. La flexibilidad se establece en dos vertientes: enmiendas en los requisitos del adoptante y en la acción de privación de custodia y en la patria potestad.

La ley 8, en la exposición de motivos identifica como problema "la cantidad de niños abandonados y desamparados que va en escala ascendente" como la razón principal para enmendar la anterior ley de adopción. Del estudio que realizamos de los documentos no se evidencia la fuente para tal aseveración, tampoco se habla de las razones para que los padres/madres abandonaran el servicio, por lo tanto a los menores en custodia del Estado. Se esgrime que la 
obligación del estado de entrar a considerar el problema, surge de un mandato constitucional y la necesidad de proteger a los menores siendo estos ciudadanos vulnerables, por su incapacidad de auto protegerse. La política pública establecida con la Ley 8 es, "promover el bienestar y mejor interés de los menores y protegerlos de estar expuestos a condiciones y experiencias que sean nocivas a su desarrollo físico, emocional y moral". No se estableció una estructura o reglamentación para la entrega del menor por iniciativa de los padres o las madres.

El propósito de la Ley 9 del 19 de enero de 1995 fue enmendar y añadir a la Ley de Procedimientos Legales Especiales aquellos artículos relacionados al procedimiento utilizado para procesar las peticiones de adopción. De igual manera enmendó el artículo 10 de la Ley Orgánica del Departamento de Servicios Sociales para que fuera cónsona con los procedimientos establecidos en la Ley 9. La Ley 9 establece como política pública, que "el fin primordial que anima todo proceso de adopción, es el bienestar y conveniencia del adoptado y el principio de que la intervención del estado sea intensa para asegurarles los mejores padres". En esta ley se dispone un procedimiento expedito, flexible, confidencial, simple y sencillo y cuyo trámite total no exceda de ciento veinte (120) días, desde su inicio hasta su resolución final. Además le garantiza a los menores el derecho a una familia con carácter permanente.

Es pertinente preguntarse, ¿Conocían los legisladores y legisladoras las limitaciones de recursos humanos y fiscales del aparato gubernamental para trabajar en el regreso de los menores a su hogar de origen? ¿Qué estrategias para medir la efectividad en la intervención se utilizaron? ¿Qué evidencias presentó el aparato gubernamental, sobre los recursos utilizados para 're educar' a los padres y madres? Poder contestar estas preguntas nos pondría en mejor posición de identificar si realmente los menores fueron abandonados por sus progenitores o si estos no recibieron ayuda efectiva para recuperarlos.

En mayo de 1980, la legislatura de Puerto Rico aprobó la Ley 75, con el fin de establecer la política pública con relación a la protección de menores y las medidas encaminadas a subsanar ese problema. En aquel momento no existía. una ley que describiera y reconociera los delitos que se cometieran en la figura del menor, por sus progenitores o por otras personas o instituciones que asumieran su cuidado por horas, días o temporeramente. El Departamento de Servicios Sociales, ahora Departamento de la Familia, fue 
la agencia gubernamental comisionada para que hiciera cumplir la política pública. Como medida de protección y tiempo de espera por los cambios en conducta y actitud de padres, madres y mejoras en la condición de sus hogares, los menores eran removidos y ubicados en hogares de crianza, hasta el momento de ser reintegrados al hogar de procedencia. Mientras esto sucedía, no se evidenció tener estrategias conducentes a prevenir situaciones que provocaran la remoción de menores del hogar.

El incremento en las situaciones en las cuales el estado tenía que intervenir para proteger a menores y el protocolo de intervención social -el cual establecía los procedimientos para intervenir y los esfuerzos razonables para el cambio por parte de los padres- propiciaron el incremento de menores en espera de regresar al hogar. El Departamento había solicitado y obtenido la Patria Potestad de menores, cuyos progenitores no evidenciaron posibilidad de rehabilitación, de acuerdo a las expectativas del Estado y al protocolo de intervención de la agencia. Según la Oficina de la Administración de Tribunales (Rodríguez, 1994), durante el año 1992 se presentaron 359 peticiones de adopción, declarando con lugar la demanda en 252, quedando pendientes de adjudicar 498 (incluye los no finalizados de 1991). Entre julio y junio de 1994 se radicaron 513 solicitudes, para un total de 1011, adjudicando 532 adopciones, quedando rezagados el resto de los menores en hogares sustitutos. Esta realidad estadística, unida a la percepción que tenía la ciudadanía de que no se adjudicaban más adopciones por las leyes y procedimientos utilizados por el Estado, movió al ejecutivo a someter un proyecto de ley dirigido a enmendar el Código Civil y la Ley de Procedimientos Legales Especiales. La legislatura realizó vistas públicas con la intensión de obtener la visión de los diversos sectores civiles y gubernamentales interesados en el tema y que de alguna manera propiciaron que el Ejecutivo enviara la pieza legal. Padres y madres de menores en hogares de crianza no participaron, no fueron convocados, el enfoque de la ley los excluyó.

Todas las voces escuchadas coincidían en que los escollos para la pronta adopción eran procesales y relacionados al enfoque de intervención social del Departamento de Servicios Sociales. Por ejemplo, la Fundación Pro-Ayuda de Puerto Rico, 1994, por medio de su representante expuso: "queremos ser portavoces de aquellos pequeños que no son escuchados en foros como éste"; "como grupo de voluntarios al servicio de Hogares de Crianza y como Junta Revisora de los Planes Permanentes para Niños Removidos, estamos ante ustedes" "sería conveniente redefinir el concepto (familia)... y aunque suene sacrílego y quijotesco, ver si en los casos de paternidad crasamente 
irresponsable, ¿no es la Patria Potestad un privilegio, en lugar de un derecho?" "piensen que Jesús nos dijo que todo lo que hicieran por mis pequeñitos, por mi mismo lo hacéis". Además señalaron:

.....los trabajadores sociales temen al riesgo de que sus estudios no sean aceptados porque no arrojan información a tono con los criterios ya establecidos para liberar la Patria Potestad. Esto sucede porque dentro de las causales para liberar, no se ha tipificado la conducta del padre irresponsable.

A pesar de la mención de los trabajadores sociales, éstos no estuvieron representados por el Colegio de Trabajadores Sociales o por una representación de los que realizaban estas funciones.

El Hogar Cuna San Cristóbal representado por el Dr. Espinosa López, consignó las siguientes expresiones: "la adopción, única alternativa permanente para muchos de los menores que merodean...es un proceso clave y al presente no se facilita"; "no hay razón para que buenos ciudadanos opten por ir fuera del país"; "los Tribunales necesitan de estos cambios para que recibiendo instrucciones especificas, dejen de ser temerosos al privar, liberar y permitir la adopción de un menor"; "exigimos que todo proceso de adopción permita la intervención voluntaria de instituciones privadas como la nuestra"; "nos preocupa el concepto bienestar del padre biológico, que creemos ha sido expandido sin razón a la familia extendida". Añadieron:

.....mientras el Estado se esfuerza por atacar estos
desgraciados males (sociales) los efectos de aquellos son
inevitables y se van convirtiendo en estadísticas
almacenadas en las gavetas y en los archivos de lo que
llamamos las arañas de la burocracia que van tejiendo las
fuertes telas que estorban las iniciativas de los nuevos líderes
del país y de ciudadanos particulares organizados....para
ayudar... para genuinamente intervenir.

Esta referencia sobre la situación de los menores podría aplicarse al trabajo realizado con los padres biológicos. Las legislaciones no solo excluyen las voces de los padres biológicos, sino que además los excluyen al momento de establecer estrategias dirigidas específicamente a las necesidades que puedan presentar este sector. 
La profesora Carmen Guemárez en calidad de Trabajadora Social y docente de la Facultad de Ciencias Sociales de la Universidad de Puerto Rico Recinto de Río Piedras, expresó lo siguiente: "las dificultades emanan de la estructura del Departamento de Servicios Sociales". Sobre el tiempo que toma determinar si el menor es candidato a adopción "de ahí surge que el Departamento tenga lista de espera de candidatos a padres adoptantes"; "las familias adoptantes prefieren infantes entre 0 a 3 años, saludables física y emocionalmente"

Como voz del aparato gubernamental, Carmen Rodríguez, Secretaria del Departamento de Servicios Sociales, compareció a las vistas y expresó el apoyo de la agencia a la medida, con la única oposición de que se le concediera adopción a las parejas que vivan consensualmente. Este señalamiento resalta los prejuicios del estado representado por la Secretaria del Departamento sobre el concepto familia y quienes componen la misma. En el Informe de la Comisión de lo Jurídico Civil, a la Cámara de Representantes, Leonides Díaz, estableció que: "la ventaja de la adopción es de proteger a los niños abandonados o huérfanos, ha hecho que se reconozca la institución aunque con otros caracteres de los que tenia antiguamente"; "el principio rector y finalidad...es el beneficio del adoptado lo que debe predominar, frente a las ventajas que pueda ofrecer al adoptante".

El documento que recoge la Discusión del Proyecto del Senado 899, contiene una reflexión de los legisladores en la que establecen su posición frente a la Adoption Assístance and Child Welfare Act de 1980 la cual tenía que considerar el Departamento para la elaboración de los planes de servicio: "la presente medida tiene por objeto que el estado cumpla con la legislación federal, pero nunca en perjuicio de los menores". En el Informe del Senado, 1994, Orestes Ramos, Presidente de la Comisión de lo Jurídico, expresó lo siguiente: "las vistas públicas produjeron una cantera de información sobre la situación real de los niños maltratados...que demostró la necesidad de revisar la normativa con relación a las áreas de adopción"; "sobre este principio el interés del menor constituye interés apremiante...y cualquier duda o controversia debe resolverse a favor del menor y ni las conveniencias administrativas, ni la necesidad de obtener fondos federales por parte del Estado, pueden prevalecer"; "aún cuando existe una política pública para promover la rehabilitación de los adictos, no puede utilizarse a un menor como mero instrumento para la rehabilitación del padre".

En la Exposición de Motivos del Proyecto del Senado 899, convertido en la Ley 9 de enero de 1995, Orestes Ramos expresó que: 
....en nuestra sociedad actual se lleva a cabo por parte de nuestro gobierno una guerra franca contra la criminalidad. En ese contexto, merecen particular atención los menores maltratados, abandonados y desamparados, para los cuales el mecanismo de adopción supone el que puedan formar parte de hogares estables.

En la Exposición de Motivos del Proyecto de la Cámara 1607, convertido en la Ley 8 de enero de 1995, el legislador expresó: "es imperativo flexibilizar la institución de la adopción para que ésta pueda ser utilizada ampliamente por personas que desean adoptar menores de edad".

Todos los textos citados anteriormente, fueron extraídos de los documentos escritos que recogen las voces de los convidados y comparecientes al análisis de la pieza legislativa generada desde el Ejecutivo. La misma pretendía satisfacer las peticiones de revisión de los potenciales padres y madres adoptantes y de agrupaciones privadas que prestan servicios a la población de menores servidos por el Departamento. De estos documentos surge endoso total a la medida.

Las personas expositoras coincidieron en que había llegado el momento histórico que exigía reacción ante el aumento del crimen, aumento en la cantidad de usuarios de sustancias ilegales y aumento de personas con problemas de salud mental. Igual identificaron el aumento en la cantidad de intervenciones con menores maltratados ubicados en hogares de crianza o sustitutos, disminución de recursos fiscales para atender esas situaciones, recursos profesionales con poco adiestramiento y pocos recursos humanos para atender la cantidad de situaciones que se presentaban, como factores que merecen reflexión. La determinación del Estado para entregar al sector privado el manejo de problemas públicos, disminución de la tolerancia de la ciudadanía ante ciertos eventos y la actitud de los tribunales frente al despojo de los derechos de los padres biológicos, también fueron señalados como factores que mueven a la acción.

Se evidencia además, como los grupos cívicos o sin fines de lucro, descartan viejas estrategias para solucionar un problema, atender menores hasta que sus progenitores se habiliten, sugiriendo soluciones permanentes que les garanticen la potestad sobre los menores. Tales expresiones nos hacen pensar que transcurrido un tiempo, la ciudadanía no reconoce competencia al 
Estado para solucionar un problema y por otro lado ha dejado atrás la esperanza de que los humanos, sus conciudadanos, puedan lograr cambios positivos en sus vidas, con acciones positivas y constructivas. De acuerdo a Kisnerman (2005): "hoy, el Trabajo Social se plantea la organización de grupos humanos para transformar situaciones problemas, buscando elevar la calidad de vida de la población con la que trabajamos, en una sociedad más solidaria". Esto último deseamos rescatarlo como un fundamento ideológico de la profesión de trabajo social con el cual estamos comprometidas para hacerlo realidad.

De igual manera vemos al Estado con una visión enmarcada en la globalización y en la reinvención del Estado Benefactor, analizando un problema desde lo costo - efectivo, desde la visión de mano dura contra el criminal. La situación planteada en las leyes, no responde a la búsqueda de la raíz del problema. Es un remedio que le permite salir de la responsabilidad frente al mismo. Es un esfuerzo que ignora las voces de los que son privados permanentemente de la Patria Potestad de sus hijos y que servidos por el estado haciendo énfasis en sus fortalezas y en la inclusión en los procesos sociales, les permitiría retener a sus hijos. Ante esta realidad surge la necesidad de replantearse la adopción como proceso social, no como acto sujeto al castigo, sino como acto que emana del amor y reconocimiento real del bienestar del menor. De igual manera la política pública debe contener un freno a las privaciones de Patria Potestad con la única intención de conceder una adopción.

\section{Construcción social de la adopción}

Se puede detallar ciertos elementos, y supuestos que, vistos en conjunto, podrían representar algo como una "perspectiva construccionista", o como dice Ibáñez (1994) un "movimiento". La construcción social considera el discurso sobre el mundo no como una reflexión o mapa del mundo, sino como un dispositivo de intercambio social. Intenta ir más allá del empirismo y el racionalismo al ubicar el conocimiento dentro del proceso de intercambio social (Gergen, 2002). Para ello, plantea cuatro hipótesis: (1) Lo que consideramos conocimiento del mundo no es producto de la inducción o de la construcción de hipótesis generales, como pensaba el positivismo, sino que está determinado por la cultura, la historia o el contexto social. (2) Los términos con los cuales comprendemos el mundo son artefactos sociales, productos de intercambios entre la gente, históricamente situados. (3) El grado hasta el cual una forma dada de comprensión prevalece sobre otra no depende fundamentalmente de la validez empírica de la perspectiva en 
cuestión, sino de las vicisitudes de los procesos sociales. (4) Las formas de comprensión negociadas están conectadas con otras muchas actividades sociales, y al formar así parte de varios modelos sociales sirven para sostener y apoyar ciertos modelos excluyendo otros. Alterar descripciones y explicaciones significa amenazar ciertas acciones e invitar a otras.

La construcción social de la adopción implica el reconocimiento de la existencia de múltiples realidades construidas por actores individuales. $\mathrm{La}$ creación continua de significado y realidad es un fenómeno intersubjetivo que se da en el mundo de la vida (Kisnerman, 2005). Siendo, la 'verdad' de la adopción una que no es única, que surge como una configuración de los diversos significados e interpretaciones que cada persona le da a la adopción. Existen opiniones diversas sobre el proceso de adopción, su complejidad, efectividad y eficiencia.

Los lazos de sangre y sus simbolismos han sido importantes en la formación de actitudes hacia la adopción. La cultura del nacimiento constituye un serio obstáculo para la aceptación social de la adopción (Lebner citado en Ambert, 2005). La fertilidad de la mujer todavía se considera una marca importante de autoestima y del reconocimiento social a pesar de la liberación de las normas de los papeles del género (Letherby citado en Ambert, 2005). La madre biológica está a menudo considerada superior a la madre adoptiva, aún por algunas feministas. La particularidad de este concepto reside en haber afianzado en el imaginario social la idea de 'instinto' en cuanto innato, natural, mecánico y necesario, casi como si se tratara de adquirir involuntariamente los valores de la bondad, el amor y el sacrificio una vez producida la activación de la capacidad gestante. En este marco ideológico, la entrega de un hijo o hija en adopción constituye una de las transgresiones más relevantes de este mito, ya que la renuncia al hijo/a-cualquiera sea el motivo que genere-, implica siempre la negación del espíritu de sacrificio y abnegación que caracteriza al ser maternal (Altamirano, 2002).

La adopción es experimentada en forma diferente tanto por los adoptados mismos que por los padres adoptivos y biológicos (Ambert, 2005). Es un proceso que beneficia tanto al padre biológico que entrega al menor voluntariamente como al padre adoptivo. El primero porque es incapaz de proveerle cuidado al menor o tienen serios problemas en sus vidas. Los padres adoptivos se benefician porque su deseo mayor es el tener descendencia, se sienten realizados y se perpetúan. El menor se beneficia, aunque aún no ha sido documentado mediante una investigación. 
La promulgación de las leyes 8 y 9 del 19 de enero de 1995 establece la institución de la adopción como mecanismo para proteger a menores, que como población vulnerable está expuesta a situaciones de maltrato y negligencia por parte de sus progenitores o tutores, obligando al Estado a procurarles un hogar estable y seguro en un corto período de tiempo. Nuestro más alto foro judicial, en Zapata Saavedra V. Zapata Martínez (2002) DTS 024, estableció "que la ley de Adopción es constitucionalmente válida" por lo que esa protección y amparo que consignan las leyes 8 y 9 responden a nuestro decreto constitucional y tiene la capacidad de obligar a la acción.

La literatura revisada sobre las leyes de adopción, ponencias y artículos de prensa presentan la adopción como la solución a un problema de violencia hacia la niñez. La sociedad puertorriqueña ha expresado a través del ejecutivo, legislador y tribunales, su endoso al acto de adoptar, siempre que se lleve a cabo para dar a un niño el hogar que sus padres y madres biológicos/as le niegan por negligencia. El Código Civil de 1930, en su Articulo 166, establece que "la Patria Potestad conlleva la obligación de ejercerla responsablemente". La Fundación Pro Ayuda de Puerto Rico, en su ponencia en las vistas públicas antes citadas planteó que "para los casos de paternidad crasamente irresponsable ¿no es la Patria Potestad un privilegio"?

El Tribunal Supremo, en Virella Archilla y Procuradora de Familia (2001) TSPR114, expone que "la adopción es producto de nuestra autoctonía", "debe servir el propósito de proteger al menor, cuidando siempre que no se le separe indebidamente de sus padres". La Iglesia Católica, en el Boletín Consideraciones sobre la Uniones Homosexuales, 2003, expresa la preocupación de que "se legalicen de manera general dichas uniones y se habilite la posibilidad de adoptar, ya que la bipolaridad sexual crea obstáculos al desarrollo normal de los niños". Esa nueva realidad interfiere con la verdad única de la Iglesia, de que el matrimonio debe ser entre hombre y mujer con el fin de la procreación. Ésta posición de la Iglesia contextualiza sectores de la sociedad puertorriqueña, que no está dispuesta a amparar y proteger a un menor, utilizando como recurso un hogar formado por una pareja homosexual. Puerto Rico como país con raíces cristianas muy arraigadas apoya la posición de la Iglesia Católica. Esto queda sustentado cuando en una investigación realizada, La adopción en Puerto Rico a 1998, un grupo de trabajadores y trabajadoras sociales indican que no darían un menor en adopción a una pareja homosexual o lesbiana y que prefieren dar la adopción a una pareja heterosexual (López, Marín y Velásquez, 1998). Este señalamiento evidencia el prejuicio y estigmatización que se adjudica a las 
diferencias sociales. Los mismos no sólo son manifestados por profesionales trabajo social, con la responsabilidad de llevar a cabo el proceso de adopción, sino también es exhibido abiertamente por representantes del Estado. Ejemplo de ello se observa en los elementos de discrimen y estigmatización presentes en la discusión de la revisión del Nuevo Código Civil, donde se ha intentado elevar a rango constitucional el matrimonio entre hombre y mujer siendo esta una de las representaciones más burdas sobre la enorme resistencia a los cambios sociales y la aceptación de la diversidad en las relaciones humanas en nuestra sociedad puertorriqueña. El Código Civil impacta todas las esferas de convivencia social. Por lo tanto, si el mismo está plagado de discrimen e intolerancia hacia las diferencias esta construcción no sólo se transmitirá al proceso de adopción sino a todos los servicios dirigidos a la ciudadanía. Se hace meritorio entonces cuestionar cómo se impactará el proceso de adopción ante la aprobación de nuevo Código Civil.

\section{La investigación en otros entornos}

Miall (1996) condujo una investigación en Canadá, para conocer la construcción social de la adopción. En sus hallazgos destaca que las personas participantes consideraban que el significado de familia respondía más a una familia en función que a una sanguínea. Esto desmonta la creencia de que sólo hijos e hijas biológicas enaltecen la maternidad y la paternidad. Este grupo de progenitores considera que la adopción propicia la creación de una familia que no tiene diferencia con la familia biológica.

Altamirano (2002) trata la adopción como una de las instituciones destacadas para proteger menores. Lo visualiza en tres aspectos: el ético, el legal y el social. La perspectiva ética la visualiza como alternativa o solución a un problema de unos niños y niñas que no pueden permanecer con sus progenitores. La perspectiva social, la ve como práctica de protección. En la primera se ve la entrega voluntaria, en la segunda un acto violento de privar de patria potestad. La construcción social del que no puede y el que no quiere emerge de las dos acciones. Uno es el bueno, responsable, que cede por amor; el otro es negligente y no merece conservar a su prole. En el aspecto legal meramente busca establecer un vínculo filiatorio. En su país, Argentina, tanto la entrega como el despojo están ligadas a la pobreza y a la incapacidad del Estado para suplir medios que permitan a estos padres y madres retener sus hijos e hijas. 
Una revisión del documento de 1987 que recoge el Convenio Interamericano sobre Conflictos de las Leyes de Adopción de Menores nos ilustra sobre los aspectos en que los pactantes han conciliado su visión sobre el tema, enfatizando en los aspectos procesales y legales, sobre la idoneidad del acto, para que no surjan conflictos. La adopción internacional ha tenido una expansión considerable. Solo para mencionar a Francia como ejemplo, en el 1980 tuvo 935 adopciones internacionales y en 2003, 3995, posicionándose en el segundo a nivel mundial en recibir niños adoptados. Estados Unidos ocupa la primera posición que al mirarla en conjunto con las adopciones domésticas representa el $2 \%$ o 1.5 millones del total de la población de menores de edad.

\section{La investigación en Puerto Rico}

Estudios realizados en Puerto Rico identifican la adopción como un mecanismo legal de prevención terciaría con el fin de trabajar la situación de miles de menores que quedan desamparados por un sin número de problemas sociales (Camacho, Delgado y Díaz, 2005). Esta percepción de la adopción alude a que la misma es vista cómo alternativa remediativa de un mal social. Camacho, Delgado y Díaz (2005) identifican en su investigación varios factores que inciden para que el proceso de adopción no se lleve a cabo de manera efectiva. Entre los factores que destacan se encuentran los siguientes: el Estado lleva a cabo un proceso burocrático, lento y en ocasiones inflexibles y no existe consonancia entre la Ley 177 de 2003 y las leyes de adopción 8 y 9 de 1995. Con relación a este punto señalan que la Ley 177 promueve reunificar familias mediante los 'esfuerzos razonables', de esta manera se revictimiza a los menores ya que pierden la oportunidad de pertenecer a un grupo familiar estable.

Por otro lado, en un estudio realizado con un grupo de trabajadores y trabajadoras sociales se encontró que la mayoría señaló que prefieren dar menores en adopción que devolverlos a sus padres biológicos, además, de preferir que los menores luego de adoptados no tengan ningún tipo de relación con sus progenitores (López, Marín y Velásquez, 1998). Este hallazgo nos lleva a debatir sobre si los esfuerzos razonables ofrecidos a los padres y madres biológicos/as son realmente suficientes y los más adecuados. Igualmente nos invita a reflexionar sobre cuáles son los prejuicios que se tienen sobre la población a impactar y cómo los mismos inciden en el servicio que se le ofrece. ¿Llegarán los trabajadores y trabajadoras sociales a la intervención con prejuicios en las situaciones de 
maltrato a menores? ¿Estarán visualizando desde entonces, cuales menores son candidatos a adopción?

Por otra parte para el 1994, la Secretaria de Servicios Sociales en entrevista periodística, admitió que el Estado está limitado para ayudar a las familias con graves problemas de maltrato a menores, antes de determinar dar en adopción al menor de estas (Luciano, 1994). Lo que pone en duda si realmente se están dando todas las oportunidades y servicios necesarios para rehabilitar a estas familias. Si bien es cierto que dicho planteamiento fue realizado hace más de diez años, también lo es el que el presupuesto del Departamento de la Familia no ha variado mucho en los últimos años y las necesidades de la población continúan en aumento. Esta acción permite entonces pensar que la necesidad de mayores servicios a las familias biológicas es una realidad en la actualidad.

López, Marín y Velásquez (1998) identifican en su estudio el que la mayoría de profesionales del trabajo social conoce parcialmente la política pública de adopción lo que podría evidenciar una de las razones por las cuales el proceso de adopción no es uno ágil. Asimismo se establece que el 40.9 por ciento de estos profesionales alegó no haber recibido ningún tipo de orientación para la implantación de la misma. Llaman la atención estas expresiones y plantean si el Manual de Procedimientos es una guía real y facilitadota para el proceso. La falta de orientación, ¿les lleva a interpretar el Manual? De igual manera nos surgen otras preocupaciones ante las expresiones citadas, ¿existen medidas de control de calidad que permitan evaluar los fundamentos, procesos y producto de la adopción? ¿Cómo se articulan los procesos de supervisión? ¿Está la Junta realizando el trabajo de fiscalización de manera preventiva o remediativa? En ésta investigación también se identifican algunas de las dificultades para la implantación de la Ley, destacándose la lentitud del tribunal y su falta de coordinación, la poca cooperación de los padres biológicos y dificultades en los procesos de la agencia.

Guemárez (1994) presenta algunas dificultades que enfrenta y ha enfrentado el Departamento de Servicios Sociales, actualmente el Departamento de la Familia para cumplir con los procesos de adopción. Alguna de éstas son: limitaciones de recursos fiscales y humanos, falta de capacitación continua y adecuada al personal que maneja situaciones delicadas, falta de supervisión adecuada por escasez de recursos humanos, dificultades en coordinar sus propios recursos internos y dificultad para coordinar con otras agencias. 
Entre los hallazgos de la investigación de Cardona, Navarro y Sierra (1998) se destacan que la mayoría de los padres y madres eligieron adoptar menores entre 0 a 2 años; y que la mayoría de la muestra identificó satisfacción criando un hijo o hija adoptada. En relación al grado de aceptación de los menores adoptados con su familia adoptiva identificaron los padres y madres adoptivos/as que la mayoría de los menores tenían una actitud de aceptación hacia los mismos. En la investigación se identifica que la mayoría de las personas participantes recomendaba la adopción como alternativa a otras parejas que no pudieran procrear.

Los hallazgos de esta investigación citada contrastan con los obtenidos en la de Martínez, Quiñones, Sánchez y Vargas (2004), la cual identifica entre las percepciones de los padres adoptivos que la adopción es un proceso extenuante por los sentimientos y situaciones experimentadas en todo el proceso. Dicha percepción es cónsona con la del Ejecutivo y Legislador al proponer las leyes 8 y 9 de 1995 con las que se pretendía evitar o minimizar esta percepción de parte de padres y madres adoptantes. Dentro de las necesidades identificadas por las personas participantes de dicho estudio se encuentran: la ayuda psicológica, apoyo emocional y grupos de apoyo. Se establece la necesidad de conocer el historial médico y biológico del menor pero no se sustenta el porque es necesario este requerimiento.

\section{Reflexión final}

La adopción plantea una excelente oportunidad de ofrecer a un ciudadano o ciudadana la oportunidad de crecer y desarrollarse dentro de un grupo familiar que aporte a su vida experiencias enmarcadas en el amor y aceptación. Nuestra historia habla por si sola respecto a nuestro interés en que todos los ciudadanos y ciudadanas sientan la protección de su persona, no obstante es momento de reflexionar sobre los fundamento éticos, valorativos, culturales y legales de ese acto. El compromiso de velar por la seguridad y bienestar debe ser con todas las partes involucradas en el proceso: los padres/madres que van a ser despojados/as permanentemente de su descendencia, menores que se moverán a otros escenarios familiares sin entender y en ocasiones sin consentir la acción y las personas que aspiran a convertirse en padres y madres de alguien ajeno a su línea sanguínea. El despojo de derechos, de progenitores y de su descendencia a crecer en familia, por no cumplir con las expectativas de la sociedad, no debe ser lo que dirija el acto de adopción ya que la misión del Estado es mantener la familia unida ofreciéndole múltiples alternativas para su desarrollo. Cuando surja la excepción y no quede otra alternativa, el acto de adoptar debe estar revestido del resguardo de la dignidad de todas las partes. Propiciar el que 
las parejas o mujeres u hombres que no deseen conservar la custodia de su descendencia puedan entregarlo al Estado para que ejerza su rol de "Parens Patrie" previene la intervención que fuerza y despoja.

La profesión de trabajo social por su naturaleza, función y fundamentos está llamada a iniciar acciones encaminadas a redefinir la política pública del Estado para que surja una nueva mirada hacia el interior de la adopción y sus diversos actores. Tanto la profesión como grupo profesional como los trabajadores y trabajadoras sociales que desempeñan funciones encaminadas a cumplir con esa política, debemos hacer reflexión que nos permita retomar nuestro rol aproximándolo a los postulados éticos y valorativos que sirven de cimiento a la profesión.

\section{Referencias}

Altamirano, Florencia. (2002). Niñez, pobreza y adopción ¿Una estrategia social? Un estudio de investigación desde el Trabajo Social. Argentina: Espacio Editorial.

Ambert, Anne M. (2003). The negative social construction of adoption: its effects on children and parents. Recuperado el 12 de octubre de 2005, de http://www.arts.yorku.ca/soci/ambert/writings/pdf/ADOPTION.pdf \#search='negative $\%$ 20social $\% 20$ construction $\% 20$ of\%20adoption

Ambert, Anne M. (2005). The social construction of adoption: Its effects on children and parents. Recuperado el 1 ro de noviembre de 2005, de http://www.adoption.on.ca/The $\% 20$ Social $\% 20$ Construction $\% 20$ of $\% 20 \mathrm{~A}$ doption.pdf

Ander-Egg, Ezequiel. (1995). Diccionario del Trabajo Social. Argentina: Lumen.

Camacho, Yaxna M.; Delgado, Omar \& Díaz, Olga B. (2005). La Aventura de Adoptar: Un estudio de caso alternativo Expectativas Físicas, Sociales y Psicoemocionales de los aspirantes a ser padres y madres adoptantes sobre el/la menor ideal, en el Hogar Cuna San Cristóbal en Caguas Puerto Rico a Mayo de 2005. Tesis de maestría no publicada, Escuela Graduada de Trabajo Social, Universidad de Puerto Rico en Río Piedras. 
Cámara de Representantes. (1994). Informe Comisión de lo Jurídico Civil. Sometido por el Lcdo. Leonides Díaz.

Cardona, Raquel; Navarro, Héctor \& Sierra Ervin. (1998). La Adopción en Puerto Rico a Diciembre de 1998. Tesis de maestría no publicada, Escuela Graduada de Trabajo Social, Universidad de Puerto Rico en Río Piedras.

Ciudad del Vaticano. (2003). Consideraciones sobre los proyectos para el reconocimiento legal de las uniones homosexuales. Recuperado el 1 de septiembre de 2005, de www.preb.com/amen

Departamento de la Familia. (2000). Reglamento para los servicios de adopción y adopción subsidiada. Puerto Rico: Autor.

Enmienda al Código Civil de Puerto Rico, Ley 8 del 19 de enero de 1995.

Espinosa-López, Ángel. (1994). Ponencia sobre el Proyecto de la Cámara 1607.

Fundación Pro Ayuda de Puerto Rico, 1994. Ponencia sobre P de la C 1607. Presentada ante la Comisión de lo Jurídico Civil de la Cámara de Representantes.

Gergen, Ken. (2002). El movimiento del construccionismo social en la psicología moderna. Recuperado el 12 de octubre de 2005, de http:/www.comminit.com/la/teoriasdecambio/lacth/lasld-244.html

Guemárez-Cruz, Carmen. (1994). Ponencia sobre el Proyecto de la Cámara 1607. Presentada ante la Comisión de lo Jurídico Civil de la Cámara de Representantes.

Informe Discusión del Proyecto del Senado 899 (1994). Sesión en pleno.

Kisnerman, Natalio. (2005). Pensar el Trabajo social: Una introducción desde el construccionismo ( $2^{\text {nd }}$. Ed.). Argentina: Editorial Lumen.

Ley de Procedimientos Legales Especiales, enmendada por Ley 9 del 19 de enero de 1995. 
Lex Juris Puerto Rico. (1930). Código civil de Puerto Rico, 1930 (Art.130 y seq.) Recuperado el 21 de marzo de 2005, de http://www.lexjuris.com/ LEXLEX\%5CLExcodigoc\%5Clexadopcion.htm

López, Norma; Marín, Brenda \& Velásquez, Marilena. (1998). La adopción en Puerto Rico, a Mayo 1998. Tesis de maestría no publicada, Escuela Graduada de Trabajo Social, Universidad de Puerto Rico en Río Piedras.

Luciano, María. (1994, 13 de julio). Impotentes ante el Maltrato. El Nuevo Día. San Juan, Puerto Rico.

Miall, Charlene. (1996). The social construction of adoption: clinical and community perspectives. Family Relations, 45 . Recuperado de http://socserv2.socsci.mcmaster.ca/sociology/faculty/MiallAdoption.pdf\#search ='social $\% 20$ construction $\% 20$ of $\% 20$ adoption'

Martínez, Luz; Quiñónez, Jazmín; Sánchez, María \& Vargas, Erika. (2004). Adoptar en Puerto Rico: ¡Otra historia para contar! Percepciones sobre el proceso de adopción, experiencias y necesidades de los padres y las madres adoptivas y estructuras mediadoras de la Asociación Puertorriqueña de Padres Adoptivos, a mayo de 2004. Tesis de maestría no publicada, Escuela Graduada de Trabajo Social, Universidad de Puerto Rico en Río Piedras.

Organización Estados Americanos. (1987). Convenio interamericano sobre conflictos de leyes en materia de adopción de menores. Recuperado el 9 de noviembre de 2005, de http://www.cndh.org.mx/

Pierluisi, Pedro. (1994). Evaluación legal, Proyecto de la Cámara 1607. Puerto Rico: Departamento de Justicia.

Quiñonez-Torres, José (1996). La adopción de la nueva ley de adopción en Puerto Rico. Revista Universidad Católica 35 (2). Recuperado el 29 de agosto de 2005, de

http://www.pub-jts.com/bin/gate.exe?f=dpc\&state=rcvkhq.3.36

Rodríguez de Rivera, Carmen. (1994). Ponencia sobre el Proyecto del Senado 899. 
Schmitt, Eric (1996, 5 de noviembre). Recompensa en la adopción de niños. El Nuevo Día. San Juan Puerto Rico

Senado de Puerto Rico (1994). Informe del Proyecto de la Cámara 1607, 12 ma Asamblea Legislativa 6ta sesión extraordinaria. Sometido por el Lcdo. Orestes Ramos, Presidente Comisión de lo Jurídico.

Tribunal General de Justicia (2004, 13 y 14 de mayo). Simposio sobre la Ley de Adopción de Puerto Rico. San Juan: Academia Judicial Puertorriqueña.

Tribunal Supremo de Puerto Rico. 2001, Virilla Archilla v Procuradora de la Familia. 2001TSPR114.

Tribunal Supremo de Puerto Rico, 2002, Zapata Saavedra V Zapata Martínez 2002 TSPR024.

UNICEF (2000). La Convención sobre los Derechos del Niño. Recuperado el 27 de noviembre de 2005 , de http://www.unicef.org/spanish/crc/convention.htm 